\title{
Experimental and analytical investigations on the response of structural building frames further to a column loss
}

\author{
Authors: \\ Jean-François Demonceau, University of Liège, Chemin des Chevreuils, 1 B52/3, 4000 Liège, \\ Belgium, jfdemonceau@ulg.ac.be \\ Jean-Pierre Jaspart, University of Liège, Chemin des Chevreuils, 1 B52/3, 4000 Liège, Belgium, \\ Jean-Pierre.Jaspart@ulg.ac.be
}

\begin{abstract}
Recent events such as natural catastrophes or terrorism attacks have highlighted the necessity to ensure the structural integrity of buildings under exceptional events. Design requirements are proposed in some codes but are generally not satisfactory. In particular, it is not demonstrated that, even if these requirements are respected, a structure subjected to an exceptional event will really behave properly.

A European RFCS project called "Robust structures by joint ductility" has been set up in 2004, for three years, with the aim to provide requirements and practical guidelines so as to ensure the structural integrity of steel and composite structures under exceptional events through an appropriate robustness.

The investigations performed at the University of Liège, as part of this European project, are mainly dedicated to the exceptional event "loss of a column in a steel or steel-concrete composite building frame"; the main objective is to develop a simplified analytical procedure to predict the frame response further to a column loss. The development of this simplified procedure is detailed in two complementary PhD theses: the thesis of Demonceau J.-F. and the thesis of Luu N.N.H. Present paper describes experimental and analytical studies carried out in [Demonceau, 2008]. In particular, a simplified analytical procedure for the prediction of the global frame response when significant membrane forces develop further to a column loss will be described; it allows: (i) to predict the development of the catenary action in a frame with joints subjected to combined bending moment and tension loads and (ii) to compute the requested rotation capacity at the joint level according to the loads applied on the frame.
\end{abstract}

\section{GENERAL CONCEPTS}

The loss of a column may be associated to different types of exceptional actions: explosion, impact of a vehicle,... Under some of these exceptional actions, dynamic effects may play an important role; within the performed studies, it is assumed that the action associated to the column loss does not induce significant dynamic effects. So, the performed investigations are based on static approaches.

When a structure is losing a column, the latter can be divided in two main parts, as illustrated in Figure 1:

- the directly affected part which represents the part of the building directly affected by the loss of the column, i.e. the columns and the beams (with the beam-to-column joints at their extremities) which are just above the lost column and; 
- the indirectly affected part, i.e. the rest of the building which has to resist to the loads developing within the directly affected part during the exceptional event.

At the top of the lost column (see Figure 1), different vertical internal are identified:

- the shear loads $\mathrm{V}_{1}$ and $\mathrm{V}_{2}$ at the extremities of the beams;

- the axial load $\mathrm{N}_{\text {up }}$ in the upper column;

- the axial load $\mathrm{N}_{\mathrm{lo}}$ in the lost column.

The objective of the studies performed at the University of Liège is to predict the evolution of $\mathrm{N}_{\mathrm{lo}}$ according to the vertical displacement of point "A" $\Delta_{\mathrm{A}}$ with due account of the possible membrane forces developing in the structure; from this curve, the ductility from the different structural elements may be derived and and the resistance of the indirectly affected part subjected to additional loads coming from the directly affected part may be checked.

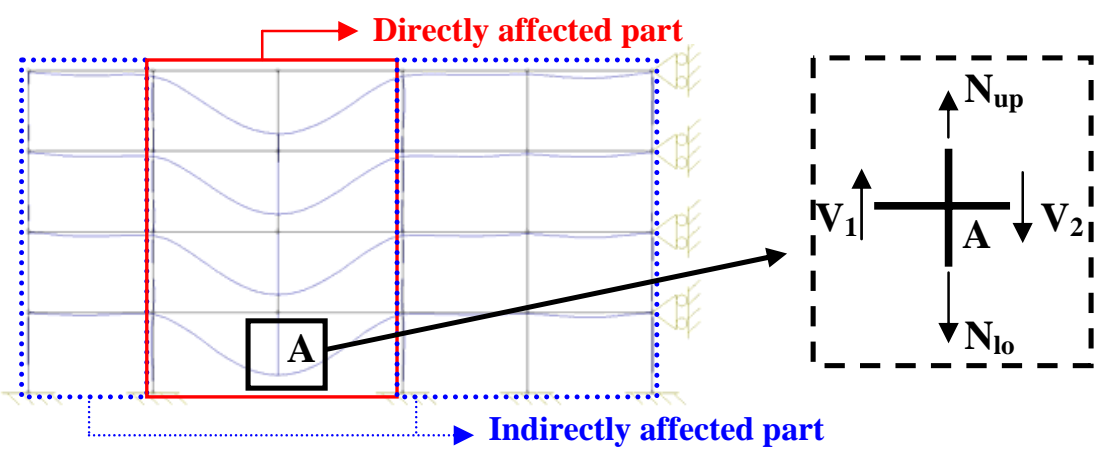

FIGURE 1 - DEFORMED FRAME FURTHER TO THE LOSS OF A COLUMN AND MAIN DEFINITIONS

In Figure 2, a curve representing the evolution of the normal load $\mathrm{N}_{\mathrm{lo}}$ according to the vertical displacement $\Delta_{\mathrm{a}}$ is illustrated:

- From point (1) to (2) (Phase 1), the design loads are progressively applied, i.e. the "conventional" loading is applied to the structure; so, $\mathrm{N}_{\mathrm{lo}}$ progressively decreases $\left(\mathrm{N}_{\mathrm{lo}}\right.$ is negative as the column "AB" is subjected to compression) while $\Delta_{\mathrm{A}}$ can be assumed to be equal to zero during this phase (in reality, there is a small vertical displacement at point $\mathrm{A}$ associated to the compression of the columns located below point " $A$ "). It is assumed that no yielding appears in the frame during this phase, i.e. the frame remains fully elastic.

- At point (2), the exceptional event occurs. From points (2) to (5), the column is progressively removed. Indeed, from point (2), the compression in column " $A B$ " is decreasing until it vanishes at point (5) where the column can be considered as fully destroyed. So, in this zone, the absolute value of $\mathrm{N}_{\mathrm{lo}}$ is progressively decreasing while the value of $\Delta_{\mathrm{A}}$ is increasing. This part of the graph is divided in two phases as represented in Figure 2:

o From points (2) to (4) (Phase 2): during this phase, the directly affected part passes from a fully elastic behaviour (from point (2) to (3)) to a plastic mechanism. At point (3), first plastic hinges appear in the directly affected part.

o From points (4) to (5) (Phase 3): during this phase, large displacements are observed in the directly affected part and second order effects play an important role. In particular, 
significant catenary actions are developing in the bottom beams of the directly affected part.

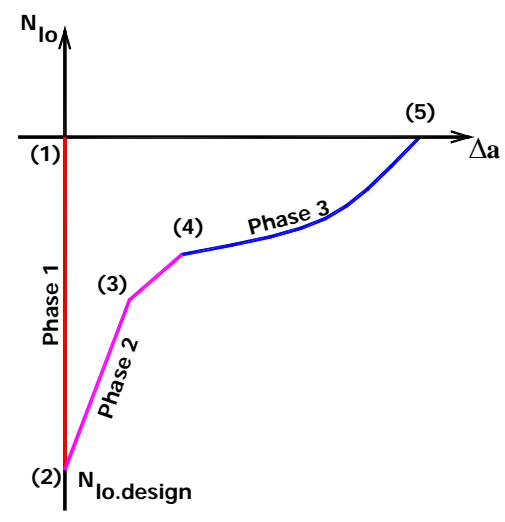

FIGURE 2 - EVOLUTION OF $\mathrm{N}_{\mathrm{lo}}$ ACCORDING TO THE VERTICAL DISPLACEMENT AT THE TOP OF THE LOST COLUMN

It is only possible to pass from points (1) to (5) if:

- the loads which are transferred from the directly affected part to the indirectly affected part do not induce the collapse of elements in the latter (for instance, buckling of columns or formation of a global plastic mechanism in the indirectly affected part);

- if the different structural elements exhibit a sufficient ductility to reach the vertical displacement corresponding to point (5).

Obviously, in some cases, the complete removal of the column could be reached (i.e. $N_{l o}=0$ ) before reaching Phase 3.

The response of the frame during Phases 1 and 2 and the behaviour of the indirectly affected part during Phase 3 have been investigated by Luu N.N.H while the response of the directly affected part during Phase 3 is the subject of the thesis of Demonceau J.-F. The strategy adopted to study Phase 3 is presented in Figure 3:

- Step 1: an experimental test is carried out in Liège on a substructure with the aim to simulate the loss of a column in a composite building frame.

- Step 2: analytical and numerical FEM tools are validated through comparisons with the experimental results

- Step 3: parametrical studies based on the use of the models validated at step 2 are carried out; the objective is to identify the parameters influencing the frame response during Phase 3.

- Step 4: a simplified analytical method is developed with due account of the parameters identified at step 3 and validated through comparisons with the experimental test results of step1. 


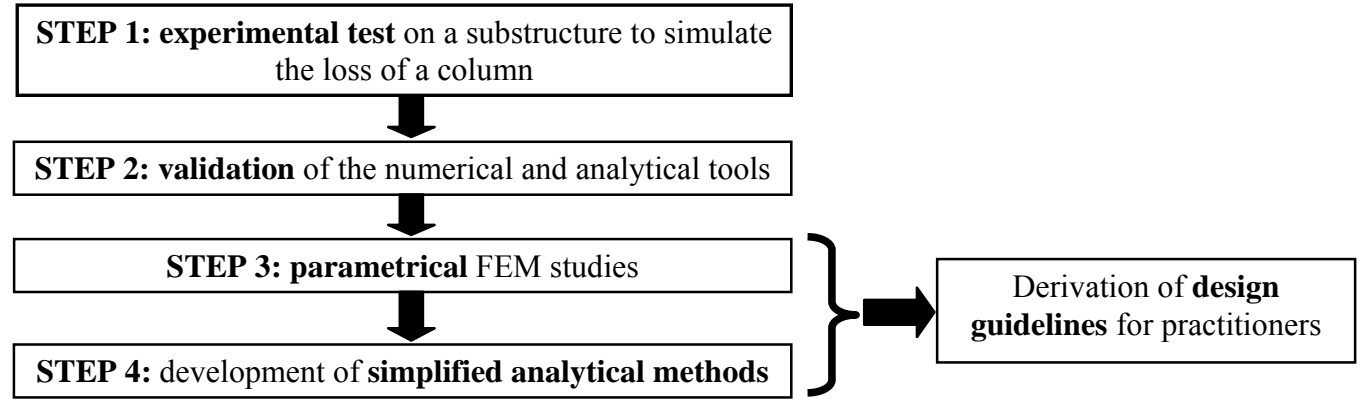

FIGURE 3 - STRATEGY FOLLOWED AT THE UNIVERSITY OF LIÈGE TO INVESTIGATE PHASE 3

In the present paper, part of the investigations conducted within steps 1,2 and 4 are reflected. More information is available in [Demonceau, 2008], [Jaspart \& Demonceau, 2007] and [Demonceau et al, 2008].

\section{EXPERIMENTAL TEST ON A SUBSTRUCTURE}

As previously mentioned, a test on a composite substructure has been performed in Liège to simulate the loss of a column. The main objective of the test was to observe the development of catenary actions within a frame and the effect of these actions on the behaviour of the semi-rigid and partial-strength composite beam-to-column joints. Indeed these joints are initially designed and loaded in bending, but have progressively to support tensile loads as a result of the development of membrane tying forces in the beams.

To define the substructure properties, an "actual" composite building has been first designed [Demonceau, 2008] according to Eurocode 4 [NBN EN 1994-1-1, 2006], so under "normal" loading conditions. As it was not possible to test a full 2-D actual composite frame within the project, a substructure has been extracted from the actual frame; it has been chosen so as to respect the dimensions of the testing floor in the laboratory but also to exhibit a similar behaviour than the one in the actual frame. The tested substructure is presented in Figure 4; the beams and the beam-to-column joints are composite steel-concrete ones while the columns are steel ones. As illustrated, horizontal jacks were placed at each end of the specimen so as to simulate the lateral restraints brought by the indirectly affected part of the actual building when catenary actions develop.

A specific loading history is followed during the test. First, the vertical jack at the middle is locked and permanent loads are applied on the concrete slab with steel plates and concrete blocks ("normal" loading situation). Then, the vertical jack is unlocked and large displacements develop progressively at point "a" (Figure 4) until the force in the jack vanishes (free spanning of $8 \mathrm{~m}$ ). Finally, a downward concentrated vertical load is applied to the system above the impacted column and is then progressively increased until collapse.

The "vertical load vs. vertical displacement at point a" curve is reported in Figure 5. The first step of the test is illustrated by the part "OA" of the curve. The vertical reaction which is associated to the uniformly distributed load and to the self-weight of the substructure is equal to $33,5 \mathrm{kN}$ (value of the load at point "O"). From Figure 5, it can be seen that the structure is still in the elastic range when " $\mathrm{A}$ " is reached.

Then, as previously mentioned, a vertical load is progressively applied until the tested specimen collapse. During this stage, two "unloading-reloading" cycles are performed. 
From points " $A$ " to " $\mathrm{B}$ " in Figure 5, the substructure enters in the yielding stage to finally form a beam plastic mechanism at point "B" (plastic hinges at the joint level). During this stage, cracks in the vicinity of the external composite joints and yielding of some steel components of the joints are observed (mainly column web and beam flange in compression).

From points "B" to "C", a plateau is observed which means that the vertical displacements increase with a constant vertical load (equal to $30 \mathrm{kN}$ ). During this stage, the concrete cracks in the vicinity of the external composite joints (joint at point "b" in Figure 4) continue to develop and yielding spreads in the steel components. One important observation is that the concrete in the vicinity of the internal composite joint (joints at point "a" in Figure 4) crushes in compression as illustrated in Figure 6.

Horizontal jacks begin to be significantly activated at point "C" of Figure 5 which means that, at this point, membrane forces start to develop, as confirmed by the shape of the curve part "CD" in Figure 5. At point "D", the longitudinal rebars in the vicinity of the external composite joints completely collapse and consequently the external joints work as steel ones. The yielding also spreads in the different components of the internal and external composite joints. At point " $D$ ", a loss of stiffness is observed which is linked to the fracture of the longitudinal rebars in the vicinity of the external joints; indeed, when these rebars break, the tensile stiffness of the external joints decreases, what affects the development of the membrane forces.

However, it can be observed that the loss of the slab rebars do not affect the loading capacity of the substructure; indeed, after point " $D$ ", the load at the vertical jacks still increases, as illustrated by part "DE" of the curve presented in Figure 5.

This phenomenon is only possible as long as the steel connections are able to support, alone, the membrane forces developed in the system. In addition, associated to the loss of the rebars, the vertical displacements are increasing with a low variation of the vertical loads. These additional vertical displacements result in an increase of the membrane forces as confirmed in Figure 7 showing the evolution of the load in the horizontal jacks at the specimen extremities according to the vertical load in the vertical jacks (after reaching point A of Figure 5). So, the steel connections working alone have to be sufficiently resistant to support these additional membrane forces and sufficiently ductile to support the additional rotations associated to the vertical displacement. The capacity of the steel connections, working alone, to support significant membrane forces has been confirmed by tests performed in isolation at the University of Stuttgart on the substructure joint configuration [Kuhlmann U. et al, 2008].
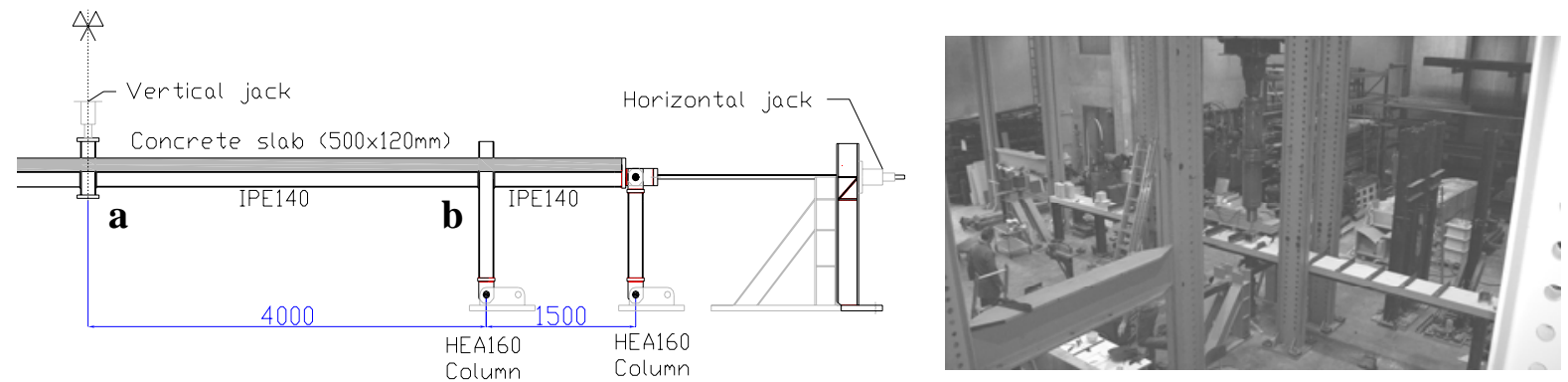

FIGURE 4 - HALF OF THE SYMETRICAL TESTED SUBSTRUCTURE 


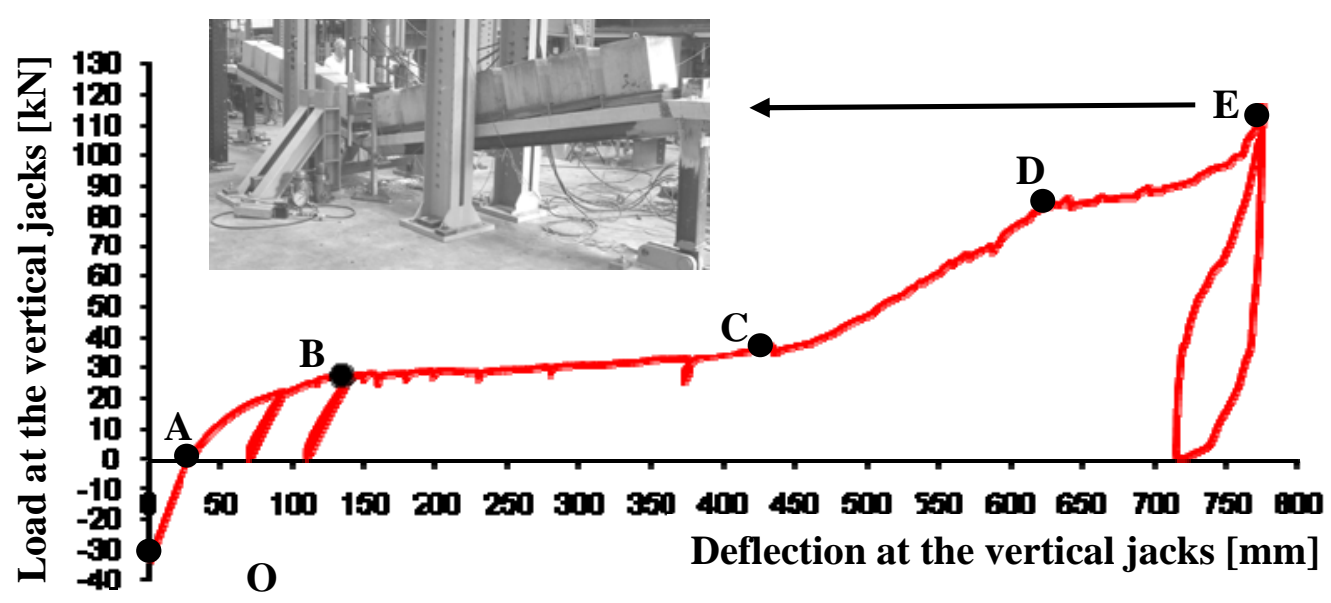

FIGURE 5 - "VERTICAL LOAD AT THE JACK VS. VERTICAL DISPLACEMENT AT POINT A" CURVE
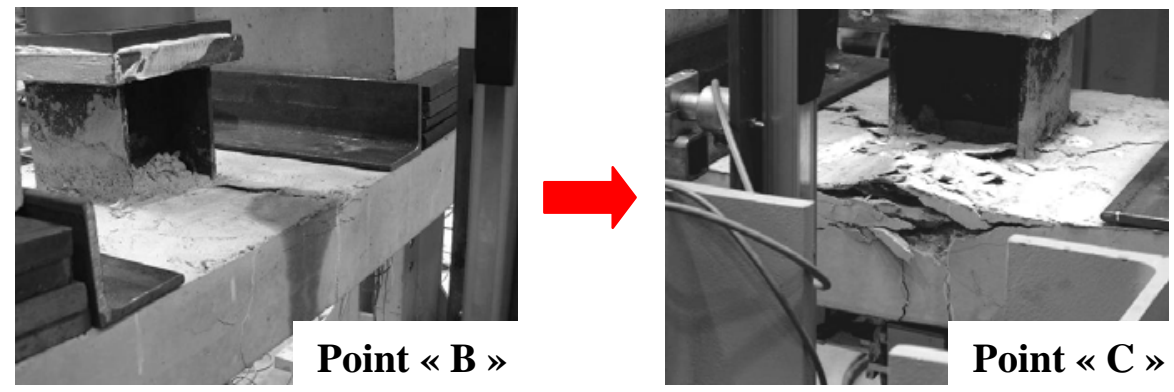

FIGURE 6 - CONCRETE SPLITTING AT THE INTERNAL COMPOSITE JOINT

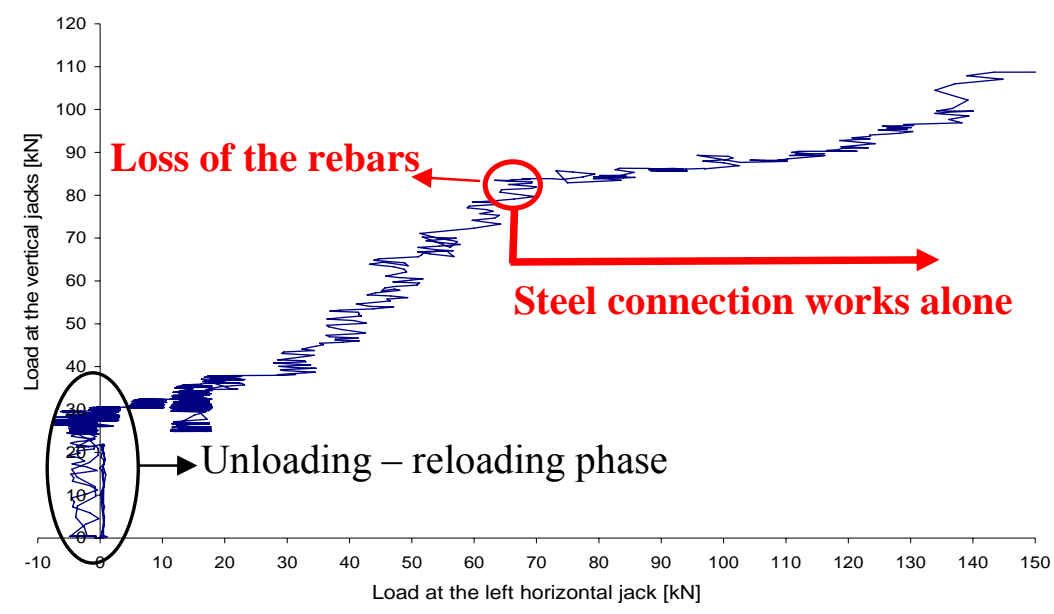

FIGURE 7 - EVOLUTION OF THE LOAD AT THE RIGHT HORIZONTAL JACK ACCORDING TO THE APPLIED VERTICAL LOAD (AFTER REACHING POINT A OF FIGURE 5)

The test stopped with the appearance of cracks at the bottom weld between the IPE140 profile and the end-plate in the internal composite joint located in "a". At the end of the test, a maximum vertical displacement of $775 \mathrm{~mm}$ is reached for a vertical load in the vertical jacks of $114 \mathrm{kN}$; the deformation of the specimen at this stage is presented in Figure 5. The maximum 
horizontal displacement at each side of the structure is equal to $45 \mathrm{~mm}$ for a horizontal load of $147 \mathrm{kN}$. The maximum rotation observed at the joint level is equal to $190 \mathrm{mrad}$.

\section{Validation of an Analytical Tool to Predict the Response of A COMPOSITE JoInt SUBJECTEd TO COMBINED MOMENTS AND AXIAL ForCES}

As previously mentioned, the structural joints during Phase 3 are subjected to combined bending moments and axial loads. In the PhD thesis of Cerfontaine F., an analytical procedure has been developed to predict the response of steel joints subjected to such a loading. The proposed method is based on the component method which is recommended in the Eurocodes for the design of joints subjected to bending moments. In [Demonceau, 2008], this method is extended to composite joints. The particularity of composite joint configurations is the fact that two main additional components are activated when compared to steel ones: the slab rebars in tension and the concrete slab in compression. As the analytical procedure presented in [Cerfontaine, 2004] is based on the component method concept, the latter is easily extended to composite joints by including the behaviour of the two additional components into the procedure. However, the characterisation of the component "concrete slab in compression" is not yet available in the actual codes; accordingly, an analytical method to characterise this component in terms of resistance and stiffness is proposed and validated in [Demonceau, 2008].

The extended method is validated through comparisons to results from experimental tests performed at Stuttgart University on the tested substructure joint configuration [Kuhlmann et al, 2008]. The comparisons are given in Figure 8. On the latter, it can be observed that two analytical curves are reported: one called "plastic resistance curve" which refers to yield strengths of the materials and one called "ultimate resistance curve" which refers to ultimate material strengths.

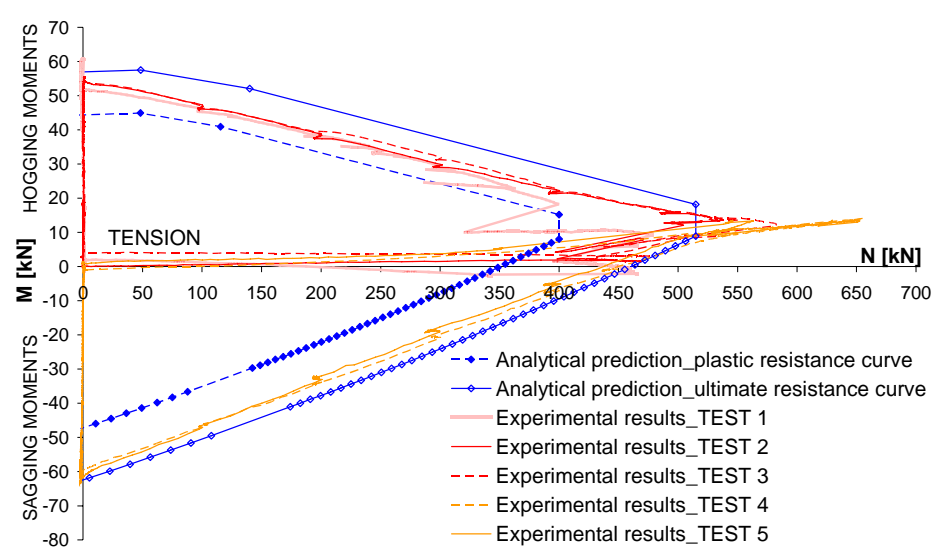

\section{FIGURE 8 - COMPARISON OF THE INTERACTION RESISTANCE CURVES}

In Figure 8, the computed analytical curves are seen to be in very good agreement with the experimental ones. Indeed, the experimental curves are between the plastic and ultimate analytical resistance curves what is in line with the loading sequence followed during the tests. The fact that the maximum tensile load reached during the experimental tests is higher than the one analytically predicted can be explained by membranar forces developing in some joint components, forces which are not yet taken into account in the analytical method. 


\section{Development of an Analytical Method to Predict the Response of a STRUCTURE WITH ACCOUNT OF THE MEMBRANE EFFECTS}

Through numerical investigations [Demonceau, 2008], it has been shown that it is possible to extract a simplified substructure (see Figure 9) able to reproduce in itself the global response of a complete frame further to a column loss. The objective is therefore to develop an analytical procedure which could predict the behaviour of the substructure in the post-plastic domain, i.e. after the formation of the beam plastic mechanism in the substructure; accordingly, the analytical model is based on a rigid-plastic analysis. Also, as the deformations of the substructure are significant and influence its response, a second-order analysis is conducted.

The parameters to be taken into account in the developed procedure are presented in Figure 9:

- $\quad \mathrm{p}$ is the (constant) uniformly distributed load applied on a storey of the considered structure and the concentrated load Q simulates the column loss $\left(=\mathrm{N}_{\mathrm{up}}-\mathrm{N}_{\mathrm{lo}}\right)$, see Figure 1); however, it is demonstrated in [Demonceau, 2008] that $\mathrm{p}$ can be neglected when investigating Phase 3;

- $\mathrm{L}$ is the total initial length of the simplified substructure;

- $\Delta_{\mathrm{Q}}$ is the vertical displacement at the concentrated load $\mathrm{Q}$ application point;

- $\delta_{\mathrm{K}}$ is the deformation of the horizontal spring with a stiffness $\mathrm{K}$ simulating the lateral restraint coming from the indirectly affected part;

- $\delta_{\mathrm{N} 1}$ and $\delta_{\mathrm{N} 2}$ are the plastic elongations at each plastic hinges;

- $\theta$ is the rotation at the plastic hinges at the beam extremities.
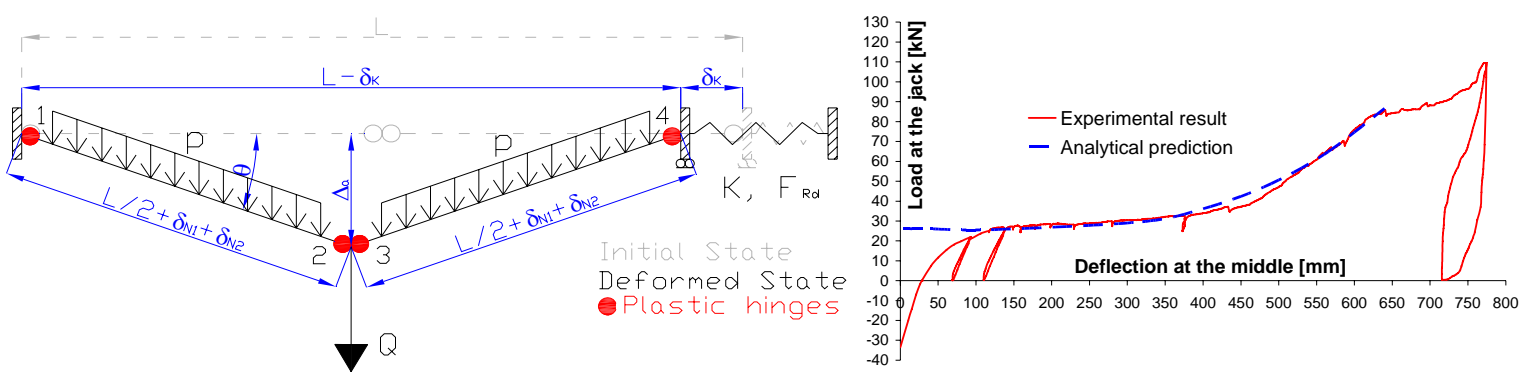

FIGURE 9 - SUBSTRUCTURE TO BE INVESTIGATED AND COMPARISON OF THE ANALYTICAL PREDICTION TO THE EXPERIMENTAL TEST RESULTS

In addition, the axial and bending resistances at the plastic hinges $N_{R d 1}$ and $M_{R d 1}$ for the plastic hinges 1 and 4 and $N_{\mathrm{Rd} 2}$ and $\mathrm{M}_{\mathrm{Rd} 2}$ for the plastic hinges 2 and 3 have also to be taken into account (it is assumed that the two plastic hinges 1 and 4 and the two plastic hinges 2 and 3 (see Figure 9) have respectively the same resistance interaction curves).

In order to be able to predict the response of the simplified substructure, the parameters $\mathrm{K}$ and $F_{R d}$, characterising respectively the stiffness and the resistance of the indirectly affected part when subjected to horizontal loads, have to be known. In [Luu N.N.H., 2008], analytical procedures have been defined to predict these properties.

Through the developments presented in [Demonceau, 2008], two expressions, (1) and (2), are respectively proposed i) for the evolution of the membrane forces $\mathrm{N}_{\mathrm{Rd}}$ developing in the substructure according to the variables $\mathrm{Q}$ and $\theta$ and ii) for the evolution of $\mathrm{Q}$ according to the variables $\mathrm{N}_{\mathrm{Rd}}, \mathrm{M}_{\mathrm{Rd} 1}, \mathrm{M}_{\mathrm{Rd} 2}$ and $\theta$ (the other parameters are constant values): 


$$
\begin{aligned}
& N_{R d}=\frac{K_{N} \cdot(\operatorname{Sec}(\theta) \cdot(2 \cdot K \cdot L+Q \cdot \operatorname{Tan}(\theta))-2 \cdot K \cdot L)}{8 \cdot K+2 \cdot K_{N} \cdot \operatorname{Sec}^{2}(\theta)} \\
& Q=\operatorname{Cos}^{2}(\theta) \cdot\left[N_{R d} \cdot \operatorname{CoSec}(\theta)-K \cdot L \cdot \operatorname{CoTan}(\theta)+\right. \\
& \frac{\operatorname{CoTan}(\theta) \cdot \sqrt{\operatorname{Sec}^{4}(\theta) \cdot\left(2 \cdot K^{2} \cdot L^{2}+N_{R d}^{2}-4 \cdot K \cdot L \cdot N_{R d} \cdot \operatorname{Cos}(\theta)+N_{R d}^{2} \cdot \operatorname{Cos}(2 \theta)+8 \cdot K \cdot M_{R d 1} \cdot \operatorname{Sin}(2 \theta)+8 \cdot K \cdot M_{R d 2} \cdot \operatorname{Sin}(2 \theta)\right.}}{\sqrt{2}}-
\end{aligned}
$$

$$
\left.K \cdot \operatorname{L} \cdot \operatorname{Tan}(\theta)+2 \cdot N_{R d} \cdot \operatorname{Sec}(\theta) \cdot \operatorname{Tan}(\theta)\right]
$$

In (1), the parameter $K_{N}$ is defined through (3) and is an average value of the plastic elongation stiffnesses $K_{\mathrm{N} 1}$ and $\mathrm{K}_{\mathrm{N} 2}$ linking the plastic elongations $\delta_{\mathrm{N} 1}$ and $\delta_{\mathrm{N} 2}$ at the plastic hinge level and the membrane forces $\mathrm{N}_{\mathrm{Rd}}\left(\mathrm{K}_{\mathrm{Ni}}=\mathrm{N}_{\mathrm{Rd}} / \delta_{\mathrm{Ni}}\right)$.

$$
K_{N}=\frac{2 \cdot K_{N 1} \cdot K_{N 2}}{K_{N 1}+K_{N 2}}
$$

Within (2), $M_{R d 1}$ and $M_{R d 2}$ can be expressed as functions of $N_{R d}$ as the bending resistances at the plastic hinge level and the membrane force $\mathrm{N}_{\mathrm{Rd}}$ are linked through the $M-N$ interaction resistance curves (of the beams or of the joints). So, Q can be expressed as a function of $\mathrm{N}_{\mathrm{Rd}}$ and $\theta$ and, by replacing $\mathrm{N}_{\mathrm{Rd}}$ by its expression given in (1) and by isolating $\mathrm{Q}$ from the so-obtained expression, as a function of $\theta$ only.

In addition, the relationship between $\Delta_{\mathrm{A}}$ and $\theta$ can be expressed through the following formula:

$$
\Delta_{A}=\left(\frac{L}{2}+2 \cdot \delta_{N}\right) \cdot \operatorname{Sin}(\theta)=\left(\frac{L}{2}+2 \cdot \frac{N_{R d}}{K_{N}}\right) \cdot \operatorname{Sin}(\theta)
$$

In conclusion, a $\mathrm{Q}-\Delta_{\mathrm{A}}$ curve can be derived as illustrated in Figure 10.

Also, it is demonstrated in [Luu N.N.H., 2008] that $\mathrm{N}_{\text {up }}$ (see Figure 1) can be assumed as constant when the plastic mechanism is formed in the directly affected part and is equal to its value at point (4) of Figure 1.

So, accordingly, the evolution of $\mathrm{Q}$ with $\Delta_{\mathrm{A}}$ from point "A" to point "B" of Figure 10 represents the evolution of $\mathrm{N}_{\mathrm{lo}}$ according to $\Delta_{\mathrm{A}}$ during Phase 3 (from $\mathrm{N}_{\mathrm{lo},(4)}$ to 0 ), as illustrated in Figure 10 (the value of $\mathrm{N}_{\mathrm{lo},(4)}$ and $\Delta_{\mathrm{A},(4)}$ at point (4) are known through the development presented in [Luu N.N.H., 2008]). In particular, it is possible to find the value of $\Delta_{\mathrm{A},(5)}$ corresponding to the complete column loss, i.e. when $\mathrm{N}_{\mathrm{lo}}$ is equal to 0 , as illustrated by the arrows in Figure 10 and, accordingly, the requested deformation capacity at the level of the plastic hinges. Also, it is possible to check if the membrane forces in the beams are smaller than the beam or joint axial resistances and if the load applied to the indirectly affected part (see Figure 1) which is equal to $\mathrm{N}_{\mathrm{Rd}} \cdot \operatorname{Cos}(\theta)$ is smaller than its resistance $\mathrm{F}_{\mathrm{Rd}}$.

The results obtained with the so-developed analytical procedure are compared to the substructure test results in Figure 9. In this figure, it can be observed that a very good agreement is obtained between the analytical prediction and the experimental results, what validates the developed method. More details about the latter are available in [Demonceau, 2008]. 


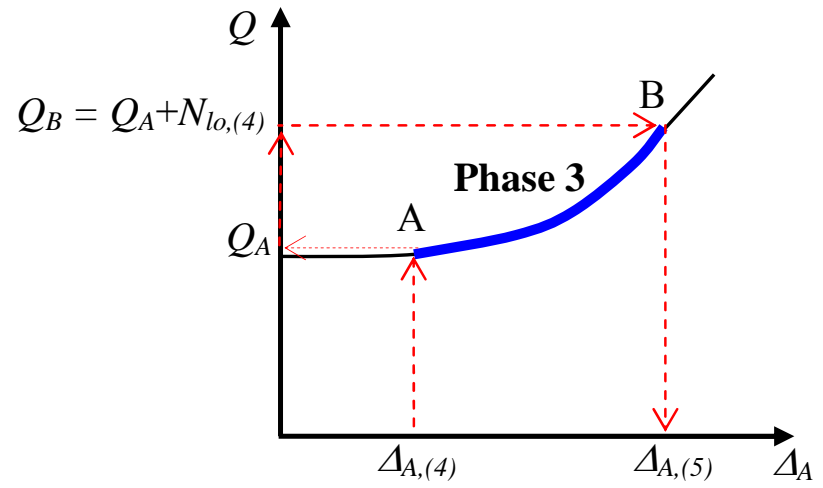

Developed analytical method

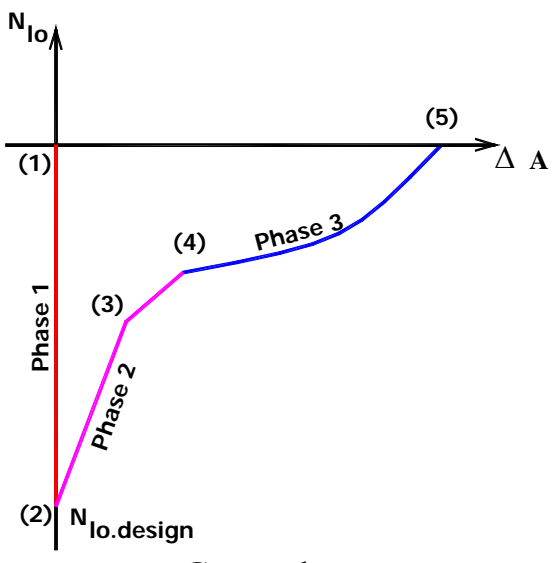

General concept

FIGURE 10 - FROM THE MODEL TO THE ACTUAL FRAME RESPONSE

\section{CONCLUSIONS}

Within the present paper, parts of the experimental and analytical investigations conducted in [Demonceau, 2008] are reflected. A general concept to study the behaviour of steel and composite frames further to the loss of a column has been first presented with a description of the followed strategy to investigate the development of the membrane effects within a structure. Then, the experimental test performed at Liège University on a substructure simulating the loss of a column in a composite building has been described. In addition, an analytical method to predict the behaviour of composite joints subjected to combined moments and axial loads has been briefly introduced. Finally, the analytical method allowing to predict the response of a structure when the membrane forces developed has been described and validated through a comparison to experimental results.

\section{REFERENCES}

[1] Demonceau J.-F., "Steel and composite building frames: sway response under conventional loading and development of membrane effects in beams further to an exceptional action", $\mathrm{PhD}$ thesis presented at Liège University, 2008.

[2] Luu N.N.H., "Structural response of steel and composite building frames further to an impact leading to the loss of a column", PhD thesis presented at Liège University, 2008.

[3] Jaspart J.-P. \& Demonceau J.F., "Contribution to the derivation of robustness requirements for steel and composite structures", Proceedings of the ICASS conference, Singapore, 2007.

[4] Demonceau J.-F., Jaspart J.-P., Klinkhammer R., Oerder R., Weynand K., Labory F. \& Cajot L.-G., "Recent development in composite connections", Journal of Steel Construction - Design and Research, Ernst \& Sohn, September 2008.

[5] NBN EN 1994-1-1, "Eurocode 4: Calcul des structures mixtes acier-béton - Partie 1-1: Règles générales et règles pour les bâtiments“, CEN, February 2006.

[6] Kuhlmann U., Jaspart J.-P., Vassart O., Weynand K. and Zandonini R., "Robust structures by joint ductility", RFCS publishable report contract $N^{\circ}$ RFS-CR-04046, 2008.

[7] Cerfontaine F., "Study of the interaction between bending moment and axial force in bolted joints (in French)", PhD thesis presented at Liège University, 2003. 